\title{
PEDAGOGÍA INCLUSIVA EN EDUCACIÓN INFANTIL: ¿CÓMO DESCUBRE EL PROFESORADO QUE HIZO BIEN SU TRABAJO?
}

\author{
Inclusive pedagogy in early childhood education: How do teachers discover that they \\ did their job well?
}

Pedagogia Inclusiva no Ensino Pré-Escolar: Como é que os professores sabem que fizeram bem o seu trabalho?

\author{
Inmaculada Concepción Orozco Almario \\ Universidad de Sevilla, España. Teléfono: +34955420601. Correo electrónico: iorozco@us.es
}

\section{Resumen}

Esta comunicación contiene algunos avances de una investigación más amplia sobre la pedagogía inclusiva. En esta ocasión, desde las voces de veintitrés docentes que desarrollan este nuevo enfoque en Educación Infantil, se narra cómo estos profesionales descubren que han realizado un buen trabajo con cada niño y niña. La metodología ha sido cualitativa, con un diseño multicaso, empleando como técnica de recogida de datos la entrevista semi-estructurada. Los resultados dejan ver algunas claves para autoevaluar la tarea educativa como son: contemplar la felicidad del alumnado, crear sólidas redes de apoyo en el aula, respetar los ritmos de aprendizaje, cooperar con la familia y apostar por la reflexión continua. Las conclusiones estiman que estas experiencias pueden ser útiles para continuar explorando cómo hacer evaluaciones más humanas en las escuelas. Palabras clave: Pedagogía inclusiva; Educación Infantil; profesorado; autoevaluación

\begin{abstract}
This communication contains some advances of a broader research on inclusive pedagogy. On this occasion, from the voices of twenty-three teachers who are developing this new approach to Early Childhood Education, it narrates how these professionals discover that they have done a good job with each child. The methodology has been qualitative, with a multicaso design, using as a data collection technique the semi-structured interview. The results show some keys for self-evaluating the educational task such as: contemplating the happiness of the students, creating solid support networks in the classroom, respecting the rhythms of learning, cooperating with
\end{abstract}


the family and betting on continuous reflection. The conclusions are that these experiences can be useful in continuing to explore how to make more humane evaluations in schools.

Keywords: Inclusive pedagogy; Childhood Education; faculty; self-assessment

\section{Resumo}

Esta comunicação contém alguns avanços de uma pesquisa mais ampla sobre a pedagogia inclusiva. Nesta ocasião, a partir das vozes de vinte e três professores que estão desenvolvendo esta nova abordagem no Ensino Pré-Escolar, narra-se como é que estes profissionais descobrem que fizeram um bom trabalho com cada criança. Foi utilizada uma metodologia qualitativa, com um desenho multicaso e utilizando como técnica de recolha de dados a entrevista semiestruturada. Os resultados mostram alguns aspetos chave para autoavaliar a tarefa educativa, tais como: contemplar a felicidade dos alunos, criar redes sólidas de apoio na aula, respeitar os ritmos de aprendizagem, cooperar com a família e apostar na reflexão contínua. As conclusões apontam que estas experiências podem ser úteis para continuar a explorar sobre como fazer avaliações mais humanas nas escolas.

Palavras-chave: Pedagogia inclusiva; Ensino Pré-Escolar; professores; autoavaliação

\section{Introducción}

Las evaluaciones y las calificaciones ocultan un componente clasificador y homogeneizador que deriva en una herramienta de control y opresión (Calderón, 2014). No obstante, este no es el sentido auténtico de una evaluación para todos, dado que esta conlleva un proceso interactivo que supone repensar la tarea docente, aprender de los errores junto al alumnado, cultivar relaciones y mejorar las acciones futuras para que cada vez sean menos excluyentes (Florian \& Beaton, 2018).

Esta comunicación se teje a partir del enfoque de "pedagogía inclusiva" (Florian, 2014), y pretende desvelar nuevas ideas sobre cómo un docente inclusivo descubre, valora y reconoce que lleva a cabo un buen trabajo con su alumnado en las primeras edades.

\section{Método}

Se ha empleado un proceso de inducción haciendo uso de la metodología de estudios multicaso (Stake, 2006), con un diseño cualitativo. Para acceder a los participantes se 
acordaron reuniones con asesores de Educación Infantil del Centro de Profesorado de la provincia de Sevilla para que ofrecieran contactos de docentes inclusivos. Después, se utilizó la técnica de muestreo por bola de nieve (Cohen, Manion, \& Morrison, 2000), obteniendo hasta el momento veintidós docentes pertenecientes al segundo ciclo de infantil (3-6 años). De estos, veinte fueron mujeres (90.9\%) y dos hombres $(9,1 \%)$, con una edad media de 42.22 años.

Los datos que se presentan forman parte de una investigación más amplia donde se elaboró un guion de entrevista semi-estructurada basada en las aportaciones de Florian (2014), Florian y Beaton (2018), Gale, Mills y Cross (2017) y Rouse (2009). En esta ocasión se expondrán algunos resultados de cuáles fueron sus acciones, centrándonos en una cuestión profunda dirigida a la autoevaluación y satisfacción docente: 1) ¿Cómo descubre que hizo bien su trabajo con cada niño y niña?

El registro de los datos comenzó a realizarse en octubre de 2018 y continúa desarrollándose actualmente. La información fue grabada cara a cara y una vez trascrita, se hizo una devolución por participante. Su privacidad y confidencialidad fue a través de consentimientos informados y seudónimos.

Por último, el análisis fue cualitativo mediante un sistema de categorías y códigos (Miles \& Huberman, 1994). El código utilizado en esta ocasión ha sido: "descubrimiento del buen trabajo". Seguidamente se han insertado cada una de las entrevistas en el software MAXQDA 12.

\section{Resultados}

La mayoría de los participantes manifestaban que sabían que habían hecho un buen trabajo gracias a la felicidad que desprendían sus niños y niñas. Ellos recurrían a la observación y se preocupaban porque su alumnado se sintiera seguro y motivado en el aula.

Karina: Creo que he hecho bien mi trabajo cuando los veo felices, disfrutando al tiempo que aprenden y avanzan en su desarrollo.

Múltiples docentes también afirmaban que observar el clima de cooperación y ayuda humana que se generaba en la clase era fundamental para autoevaluarse. Por ejemplo, varias experiencias destacaban los vínculos establecidos entre iguales y la autonomía para comprender y empatizar con el otro. 
Raúl: Cuando he originado en un niño la capacidad de ayudar a los demás. Sigue siendo la esencia del grupo lo que hace que me sienta bien en mi trabajo porque el aprendizaje si no es social, no existe.

Otra gran parte del profesorado consideraba que su labor era adecuada por su propia forma de ser, ya que daban la bienvenida a la diversidad y cuidaba con afecto la identidad de cada niño.

Rosalía: Porque sé que cada uno es de una manera, cada uno tiene un ritmo evolutivo diferente y que yo estoy respetando ese ritmo de trabajo. Entonces, para mí está bien.

La familia también era clave para el descubrimiento de un buen trabajo y lograr una evaluación compartida. La entrada de la familia al aula era signo de rendimiento académico y bienestar.

Marcela: Yo me pongo contenta cuando veo que, durante un proyecto realizado, a ellos les hace ilusión compartirlo con su familia. Esto me llena mucho.

Por último, algunos revelaban que era esencial la reflexión, la formación y evaluación permanente de sus acciones para crecer profesionalmente y ofrecer una educación de calidad.

Alejandra: Eso es muy complicado porque yo soy una persona que estoy continuamente juzgándome y viendo qué puedo hacer para hacerlo mejor. Para mí nunca es suficiente.

\section{Conclusiones}

Desde las voces de estos participantes, mejorar como docentes y mejorar los procesos de aprendizaje supone mirarse a sí mismo y devolverle a la escuela su sentido ético. Las contribuciones de Budiyanto, Sheeshy, Kaye y Rofiah (2018) sobre pedagogía inclusiva desvelaban algunas pistas, pero en esta investigación se puede apreciar otras sendas. El propio proceso de evaluación formativa se lleva a cabo mediante la observación sistemática, la escucha, la reflexión continua de la praxis, la coordinación con la familia 
y la formación continua. Es compartida porque tanto la familia como la voz del alumnado se valoran como fuente de información.

\section{Referencias}

Budiyanto, Sheehy, K., Kaye, H., \& Rofiah, K. (2018). Developing Signalong Indonesia: issues of happiness and pedagogy, training and stigmatisation. International Journal of Inclusive Education, 22(5), 543-559.

Calderón, I. (2014). Educación y esperanza en las fronteras de la discapacidad. Estudio de caso único sobre la construcción creativa de la identidad. Madrid: Cinca.

Cohen, L., Manion, L., \& Morrison, K. (2000). Research Methods in Education. London: Routledge.

Florian, L. (2014). What counts as evidence of inclusive education? European Journal of Special Needs Education, 29(3), 286-294.

Florian, L., \& Beaton, M. (2018). Inclusive pedagogy in action: getting it right for every child. International Journal of Inclusive Education, 22(8), 870-884.

Gale, T., Mills, C., \& Cross, R. (2017). Socially Inclusive Teaching: Belief, Design, Action as Pedagogic Work. Journal of Teacher Education, 68(3), 345-356.

Miles, M., \& Huberman, A. (1994). Qualitative data analysis. Thousand Oaks, C.A: Sage Publications

Rouse, M. (2009). Developing inclusive practice: A role for teachers and teacher education. Education in the North, 16, 6-13.

Stake, R. (2006). Multiple Case Study Analysis. New York: The Guilford. 